\title{
Da “humana” geografia em Maria Gabriela Llansol: da língua à escrita. De Colares a Herbais
}

\author{
Paula Mendes Coelho \\ Universidade Aberta - Centro de Estudos Comparatistas
}

Resumo: A obra de Maria Gabriela Llansol, uma das mais perturbadoras e inclassificáveis do início do séc. XXI, concebida entre vários países, línguas e culturas, permite questionar em moldes particulares a relação que estabelece com o espaço e com aqueles que o povoam. Neste ensaio estabelecem-se ligações entre os diferentes espaços - físicos, linguísticos, interiores - e a teoria llansoliana da escrita tecida a longo da sua obra, aberta a territórios mentais diversos e inesperados.

Palavras-chave: Maria Gabriela Llansol; exílio; poética do espaço; geopoética e geocrítica

Résumé: L'œuvre de Maria Gabriela Llansol, une des plus étranges du début du XXIe siècle, conçue entre plusieurs pays, langues et cultures, permet de questionner de façon très particulière le rapport qu'elle noue avec l'espace et ceux qui l'habitent. Cet essai rend compte des curieuses liaisons que l'on peut établir entre les différents espaces - physiques, linguistiques, intérieurs - et la théorie llansolienne de l'écriture tissée tout le long de son œuvre, ouverte à de multiples et inespérés territoires mentaux.

Mots-clés: Maria Gabriela Llansol, éxile, poétique de l'espace, géopoétique et géocritique 
"Eu ando a pé: penso com maior velocidade."

"Sempre me senti paisagem."

Maria Gabriela Llansol

\section{"Eu aceito qualquer lugar, menos o de me perder"1}

A obra de Maria Gabriela Llansol (1931-2008), uma das mais perturbadoras e inclassificáveis do início do séc. XXI, concebida entre vários países, línguas e culturas, e a teoria llansoliana da escrita tecida a longo da sua obra, aberta a territórios mentais diversos e inesperados, permitem questionar em moldes particulares a relação que essa obra estabelece com diferentes espaços e com aqueles que os povoam.

Nesta obra, em que Maria Gabriela Llansol recorda a certa altura o tempo da infância em que se sentia como uma "corça prisioneira", e ter sido "cercada pelo desejo de mover[se] sem fim" (Llansol 1998: 12), são inúmeras as expressões que remetem para o campo semântico da geografia. Desde o título da trilogia Geografia de Rebeldes, a obras como $O$ litoral do mundo, Lisboaleipzig, Contos do Mal Errante, ou ainda expressões como: "na periferia da madrugada", "o desejo de nomadismo", "a paisagem territorial do livro", "o lugar navega ao lado do mar onde ponho os pés", "atravesso o primeiro volume das Obras Completas de Georges Bataille", ou ainda as deliciosas "beguinas migratórias". Sem esquecermos os "vagamundos" e, finalmente, o texto que viaja...

Durante o exílio voluntário de Maria Gabriela Llansol e de seu marido Augusto Joaquim na Bélgica, entre 1965 e 1985, Maria Gabriela lê ininterruptamente. Lê e escreve. Em Lovaina, Jodoigne, Herbais, onde segundo o marido viviam social e geograficamente muito isolados. Lê sobretudo autores muito afastados das referências maiores da cultura portuguesa : filósofos e poetas alemães, místicos, pensadores rebeldes e solitários, em cuja linhagem a mais que rebelde Maria Gabriela Llansol diz integrar-se (Cf. a sua "Geografia de Rebeldes") ${ }^{2}$. Leituras que vão abalar para sempre a sua relação com o país natal, com a sua cultura de origem, com a sua língua materna, "desejando salvar-[se] através dela"(Llansol 
2013: 82). O exílio seria, com efeito, para ela, "um caminho"3; a Bélgica tornar-se-ia "a [sua] mesa de escrita". 4 Foi, pois, a partir dos lugares do seu exílio voluntário, de Herbais sobretudo, e nomeadamente a partir dos anos 80 do século passado, que aquela que afirmou que o exílio fazia " parte da escrita” e que "não o queria perder" (Llansol 2013: 208) começou a tecer um texto aberto e ininterrupto, um texto-ponte, até dar corpo a uma escrita nómada, a uma extraordinária comunidade textual.

“__Herbais, um lugar sem país no mundo__ $" 5$

Augusto Joaquim, no posfácio a Causa Amante, evoca os passeios, se assim se lhes pode chamar, pela única rua dessa aldeia, quase sempre por entre lama e pó, durante os quais falavam, "falavam sempre", observando que, enquanto ele "envolvia o ver numa rede de percepção a priori, a "escuta" de Maria Gabriela "parecia ter o condão de pôr o ver e a paisagem a vibrar em consonância” (Joaquim 1996 a:167). Acrescentando: "Eu via figuras geométricas, onde ela viria [sic], digamos, gestalts. É que nós mesmos éramos, um encontro inesperado do diverso, a criar a sua própria densidade virtual" (Ibidem: 168).

Este Horizonte-Herbais, a que chama "vale, porto hospitaleiro e lugar receptivo" (Llansol 1998: 112), simultaneamente sinónimo de fechamento e de liberdade total, “[...] em que a reclusão reina, num império absoluto de libertação"6, torna-se lugar privilegiado para escrever, vai ser o lugar escolhido para fecundar a sua paisagem textual. Ampliação radical, do sótão a Campo de Ourique onde ia "muitas vezes pensar que escrev[ia]"(Id 1998: 77), das casas, das casas de escrita que se impõem na sua geografia e desencadeiam o seu texto.

É curioso verificar o modo como a autora se refere ainda a este lugar tão significativo para a sua escrita: "Paisagem nem urbana, nem rural, com essa faixa que ainda hoje a atravessa e que sempre me dava vontade de a seguir. [...]. A este processo chamei a convicção íntima, e foi nela e suspensa da janela desse quarto que escrevi, dias a fio "Contos do Mal Errante" (Id. 2001: 117). Num pequeno texto datado de 26/08/1975, Maria Gabriela registava, em verso: "Tempo / espaço / cidade / campo / zonas intermédias / não diferenciadas, / a depauperadora / terra de ninguém" (Id. 2009: 95). 
Contudo, anotaria no seu diário em 24 de Maio 24 de 1979 : “Tenho falta de viagens. A Sintra, à Baviera, à Floresta Negra, à Umbria. Tenho falta de uma pluralidade de ecossistemas, e de cidades em que entre hoje e saia no dia seguinte" (Id. 2013: 80).

Mas o papel de Herbais ia sendo cada vez maior, sentido como "uma ilha humana", adiantando a autora, significativamente para o que aqui nos interessa: "Mas, para a compreender para além da sua pequenez, precisámos de deixar partir de nossas mentes a imagem de cidade, aglomeração humana densa" (Id. 2001: 121).

A imaginação poética de Maria Gabriela afasta-se então da cidade enquanto lugar edificado, reconhecível toponimicamente (nunca escreve sobre lugares, mas cria a partir deles...), se exceptuarmos evidentemente as referências a sítios da infância, a sua "primeira geografia" (Id.1998:137), como lhe chama: Campo d'Ourique, o no 64 da rua Domingues Sequeira a que alude inúmeras vezes na sua obra, o Camões (aqui praça e não Comuns, a figura/o viajante-língua), as idas com a mãe à Baixa, aos retroseiros, sapatarias, livrarias ("a minha viagem ancestral, a donzela de que me libertei" (Ibidem). Acrescento ainda esta evocação, pelo facto de o seu registo claramente emotivo ser excepcional na obra de Maria Gabriela: "Como é hoje belo esse caminho modesto, de lojas arcaicas, que lembram ainda gostos rurais, e encontros de aldeia" (Ibidem).

Não me atardarei sobre os cafés, sem as conotações a que estamos habituados tertúlia/debate/encontros - tornados verdadeiros lugares de escrita. Escreve sobre a "toalha branca", guardanapos e marcadores de cerveja. Na Bélgica, em Lovaina, Jodoigne, ou em Portugal, nas esplanadas sobretudo, Campo de Ourique, Sintra. Lugares onde colhe energia para a escrita, ao seu modo, claro...: "Que força/tem o mundo/visto do/ lugar em que/eu não vejo./ Estou na/esplanada/ao sol...". ${ }^{7}$

Ou ainda:

Tenho vários cafés à minha volta, mas o que prefiro é o do Jardim da Parada, com a entrada aberta sob as árvores [...] ...o seu estímulo é humano e vegetal, uma vigília do vegetal sobre o humano, e a minha vigília que os liga. 0 café padece de falta de palavras úteis; mas as inúteis são um rumor que me entrega a clorofila de que eu preciso. [...] Passo por cima de Kierk[egaard] e no chão, por debaixo da mesa, uma borboleta parda, de pé, declina. E finalmente, quando estabeleço a minha mesa voltada 
para a porta - com o desejo sublimado posto neste símbolo, ninguém no café que eu imagino .8

Mas volto à Bélgica, a Herbais-Horizonte. É a aí que, servindo-se precisamente do nome de duas cidades (bem afastadas, bem distintas), vai lançar os fundamentos para Lisboaleipzig (Id. 1998: 106), um dos seus títulos emblemáticos. Duas cidades que vai ligar num continuum, sem ponto, nem hífen, graças ao encontro de duas figuras maiores presentes no seu texto global, refiro-me a Bach e Pessoa. Eis o que nesse livro nos adianta acerca do "realismo", ela que abomina a representação realista, mas reinventa o conceito de outro modo, através da relação que a sua espantosa escrita estabelece com o mundo, com o real: "Sem provocação, diria: a textualidade é realista, se souber que, neste mundo, há um mundo de mundos, e que ela os pode convocar, para todos os tempos, para lá do terceiro excluído, e do princípio de não-contradição" (Id. 2014:130).

Contudo, a sua maior viagem vais ser na/e com a língua portuguesa, em companhia de Camões e Pessoa, por esses "espantosos viajantes do português-língua”, como ela os define: "Escrever é amplificar pouca a pouco" (Id. 1998: 37).

Foi então preciso sair de Lisboa, que a autora associa à sua saída da escrita representativa, para que se conseguisse libertar dos entraves, das normas, sobretudo mentais, para que passasse para o outro lado. Para o lado da língua: "Destituo-me da literatura e passo para o lado da língua" (Id. 2013: 81) dirá, e logo, e daí, para uma outra captação do espaço, por deslocação, o que acarreta uma espécie de memória virtual do percurso, que Augusto Joaquim esclarece ao falar em “carta geográfica móvel”, uma carta de virtualidades criada pela multiplicidade de espaços confluentes, mas virtuais, "um modo não significante de criar volume [...]. A captação permite, pois, caminhar não só sobre o espaço, mas igualmente sobre o tempo" (Joaquim 1996a: 190). Ou seja, uma realidade textual que dá conta de um devir como "simultaneidade", nas palavras de João Barrento (Barrento 2008: 343). E explica ainda Maria Gabriela noutro sítio: "Como ser civil conheço o presente, o passado, e o futuro. Mas como escritor tenho um olhar que toca sobretudo o espaço, livre de tempo. Nele não há poder, que é sempre o poder de escolher e de chegar à 
morte. [...]"(Llansol 1998: 132).

Escreve ainda Maria Gabriela Llansol:

Imaginemos, pois, que este caderno são terrenos que ocupam o olho agrimensor. Que, em cada dia, eu acordo mundo num terreno, ou noutro, ou no mesmo do dia anterior, ou em nenhum que eu identifique; que Herbais é o lugar dos descampados onde saio para os terrenos; que saio constantemente [...] (Id 2002: 313)

De terrenos e mais terrenos é também feita a escrita de Maria Gabriela Llansol: "Estou a meio caminho entre o interior e o exterior e o que devo contar, para ser compreensível [...] é como se torna efectiva uma das hipóteses de passagem" (Id. 1998: 66). De passagens entre línguas, culturas, obras. Tal como nas "traduções" que escolhe fazer: um texto seu que se situa sempre entre línguas, entre lugares, entre geografias...Delas, de que me ocupo há anos, não me atardarei aqui.

"Passagens-metamorfose", como lhes chama e lhe sugerem uma "Bruges-surLisbonne" (Id. 2015: 590), a propósito de Évora, ou lhe revelam que "Jodoigne foi a casa das beguinas, que Herbais foi o lugar de encontro de Infausta, de Aossê e de Bach, e que em Colares acabaram por encontrar-se os membros dispersos da comunidade, nos seus extractos de época, idênticos e evolutivos" (Id. 2014: 49).

Assim, a sua terceira confidência no Inquérito às Quatro Confidências, datada de 21 de Fevereiro de 1995, consiste em revelar que para ela "não há contemporâneos, mas elos de ausências presentes; há um anel de fuga. Na prática, é uma cena infinita o lugar onde somos figuras" (Id. 1996b: 48). A sua escrita será assim a da "sobreimpressão", a da "vibração dissonante", nos seus próprios termos.

Na sua obra vamos então encontrar sobretudo espaços de mediação, lugares sem hierarquias por onde circulam as figuras que povoam a sua obra, que atravessam os tempos.... Figuras que, como bem sabemos, não são personagens, mas módulos, nem coisas, nem metáforas "mas vivos"[...]"matéria leve e não coisa, algures entre o orgânico, o construído e o concebido" (Id. 2000: 190), como Maria Gabriela se lhes refere.

Claro que por trás deste espaço comum, de comunidade, existe, para além das suas 
mais profundas motivações, uma motivação ideológica/política mais imediata. Com efeito, em Herbais imaginou "sob a forma de Pessoa, um único rio cósmico que não se quebra em fronteiras", e sentiu "o desejo de que não haja países que sejam como guardas de matilhas" (Id. 1998: 112). Advertência que viria a revelar-se, infelizmente, bem actual, numa Europa que ela nunca deixou de questionar e que hoje volta a estar em crise, como não podemos deixar de constatar.

“Pôr-se de novo a caminho é o único caminho” (Id. 2014: 99)

E Portugal? E o mar?

Embora Maria Gabriela fosse muito crítica relativamente a Portugal ("essa cinzentez"); à nossa história das ideias e produção intelectual ("não temos pensadores sistemáticos"), ela, que considerava ridículo atribuir-se qualquer sentido à História, vai recuperar curiosamente o que esteve na origem do nosso passado dito dourado, ao ligar o dom poético à nossa história dos Descobrimentos, um dom de dádiva, de abertura suprema. Escreve ela: “Criámos, assim, um espaço para a evolução do possível e, sobretudo, para a emergência do imprevisível. Esse o ponto de encontro desejado da consciência livre com o dom poético" (Id. 2014: 99).

Mas atenção, demarcando-se sempre, bem entendido, dos fabricados encontros de culturas, onde se esquece o aniquilamento/ou sujeição de algumas, daí que denuncie noutro sítio a euforia das comemorações dos descobrimentos - “('encontro de culturas', lhe chamaram") (Id. 2002: 80) - que uma certa literatura alimenta:

Numa estética realista, acentuadamente cinza e ressentida, foram-lhe propostos [ao público leitor] vários 'retornos das naus'. Tudo 'coisas' muito vendidas pela indústria cultural. Sempre mais-pátria para parafrasear Antonio Guerreiro. Sempre mais-água e mais-oceano, tudo quimeras, e tão pouca terra sólida onde pousar os pés. Onde impera a estética do encontro, haverá mais afogados do que nudistas. E estes tudo farão para aparecer como `heróis do mar’. Pudera! Quem fará falar os perdidos, os excluídos e os afogados? (Ibidem.).

Respondo: ela, Maria Gabiela Llansol, à sua maneira. Veja-se o que escreveu numa 
nota datada de 15 de Agosto de 2000, muito antes das catástrofes a que vimos assistindo nos tenebrosos oceanos dos nossos dias: "Grande é a ousadia dos imigrantes, dos transmigrados, dos transeuntes. [...] 0 texto passa num mar revolto de sangue.[...]".9

Mas, curiosamente, algures no seu texto Maria Gabriela pergunta: "Penso muitas vezes: ‘E se Vasco da Gama não tivesse voltado..." (Id. 1998: 37). E não posso deixar de convocar aqui o soneto que Mallarmé compôs em 1898, publicado em Paris e em Lisboa, na primavera de 1898, num Álbum comemorativo, "sous le patronage de Sa Magesté la reine Amélie de Portugal", por ocasião do 4⿳o centenário da expedição de Vasco da Gama à India. Nesse soneto intitulado "Au seul souci de voyager", o "pálido Vasco" ("pâle Vasco"), resiste à tentação dessas "Índias esplêndidas" que procurava, resiste à tentação das riquezas almejadas, acabando por não desembarcar. O "sorriso do pálido Vasco" é o sorriso do aventureiro insatisfeito, que decidiu prosseguir a sua viagem... Recordo Maria Gabriela: "Pôr-se de novo a caminho é o único caminho".

Viajantes do espírito, "au seul souci de voyager...". Com o único intuito de viajar rumo a outras quimeras. E, uma vez que o dom poético para Maria Gabriela Llansol é "a língua tocada pela expansão do universo", só esta irá de facto propiciar e permitir o "encontro inesperado do diverso"...

Maria Gabriela disse querer desfazer o nó que liga, na literatura portuguesa, a água aos seus textos maiores, acabando por concluir: “ ...mas esse nó é muito forte, um paradigma frontalmente inatacável" (Id. 1998: 32).

É assim que o mar, um mar persiste, enquanto paisagem, na peculiar geografia figural do texto llansoliano: "Sem saber como, [ela] sabia que, no fim dessa estrada [a que atravessava Herbais] estava um mar" (Id. 2001: 117).

É que para ela os lugares não são meros cenários, ou reflexos de estados de alma, que não existem, mas são criados e transfigurados desencadeando cenas e figuras-fulgor. É assim que a geografia pessoal de Maria Gabriela, a sua pujante imaginação espacial alimentada pelas mudanças de países, lugares, sítios, desafia as questões e interpretações mais usuais que uma qualquer poética do espaço possa colocar ao seu texto: “...ando a percorrer as ruas dos meus diários para construir uma cidade que interrogue, 
incredulamente a poesia. Escolherei algumas ruas, e com fragmentos desse espaço rectilíneo formarei um labirinto com saída clara no final”. 10

\section{NOTAS}

${ }^{1}$ Maria Gabriela Llansol, Rara \& Curiosa, no 42, p. 50.

2 Trilogia "Geografia de rebeldes", que engloba O Livro das comunidades, Lisboa, Afrontamento, 1977 ; A restante vida, Lisboa, Afrontamento, 1983 ; Na casa de Julho e Agosto, Lisboa, Afrontamento, 1984.

${ }^{3}$ Id., Caderno 1.08, p. 54 [Documentos Espólio-Espaço Llansol]

${ }^{4}$ Id., Agenda 19, p. 17-18 (16.06.1982) [Documentos-Espólio Espaço Llansol]

${ }^{5}$ Id., Caderno 1.14, p. 91. [Documentos Espólio-Espaço Llansol].

${ }^{6}$ Id., Caderno 1.09, p. 353. [Documentos Espólio-Espaço Llansol].

${ }^{7}$ Id., Avulso, FAms0522, Julho 1998.

${ }^{8}$ Id., Caderno 1.21, pp 23-26, 13 de Março de 1985.

${ }^{9}$ Id, Caderno 1.59, pp 177-178.

${ }^{10}$ Caderno 1.54, 74, 3.5.99 


\section{Bibliografia}

Barrento, João (2008), Na Dobra do Mundo, Lisboa, Mariposa Azual.

Coelho, Paula Mendes (2014),“Baudelaire, Pierre Louÿs e Mallarmé: a fabulosa montagem de MG Llansol pelo desejo de traduzir animada". In Trans-Dizer Llansol. Tradutora/traduzida/transcriada, Lisboa, Mariposa Azual, pp. 71-87 (Org. João Barrento e Maria Etelvina Santos)

Joaquim, Augusto (1996a), "Posfácio”. In Llansol, Maria Gabriela, Causa Amante, Lisboa, Relógio d'Água.

Llansol, Maria Gabriela (2001), A Restante Vida [1983], seguido de “O pensamento de algumas imagens", Lisboa, Relógio d'Água.

-- (1996b), Inquérito às Quatro Confidências, Lisboa, Relógio d’Água.

-- (1994), Lisboaleipzig. O encontro inesperado do diverso, Lisboa, Rolim.

-- (2014), Lisboaleipzig. O encontro inesperado do diverso.O ensaio de música, Lisboa, Assírio \& Alvim.

-- (1984), Na Casa de Julho e Agosto, Lisboa, Afrontamento, 1984.

-- (2013). Numerosas linhas. Livro de Horas III, Lisboa, Assírio\& Alvim. Ed. João Barrento e Maria Etelvina Santos.

-- (2015), O Azul Imperfeito. Livro de Horas V, Lisboa, Assírio\& Alvim. Selecção, transcrição, introdução e notas de Maria Etelvina Santos.

-- (2002), O Senhor de Herbais, Lisboa, Relógio d’Água.

-- (2000), Onde vais, Drama-Poesia ?, Lisboa, Relógio d’Água.

-- (1998), Um Falcão no Punho. Diário I, Lisboa, Relógio d'Água. Posfácio de Augusto Joaquim. [1ํㅡㄹ.1985].

-- (2009), Uma Data em cada Mão. Livro de Horas I, Lisboa, Assírio \& Alvim. Selecção, 
transcrição, introdução e notas de João Barrento e Maria Etelvina Santos.

Documentos Espólio-Espaço Llansol:

-- Agenda 19 (16.06.1982) [Documentos-Espólio Espaço Llansol].

-- Avulso, FAms0522, Julho 1998 [Documentos Espólio-Espaço Llansol].

-- Caderno 1.08 [Documentos Espólio-Espaço Llansol].

-- Caderno 1.09 [Documentos Espólio-Espaço Llansol].

-- Caderno 1.14 [Documentos Espólio-Espaço Llansol].

-- Caderno 1.21 [Documentos Espólio-Espaço Llansol].

-- Caderno 1.54, 74, 3.5.99 [Documentos Espólio- Espaço Llansol].

-- Caderno 1.59 [Documentos Espólio-Espaço Llansol].

--Rara \& Curiosa, no 42, p. 50 [Documentos Espólio- Espaço Llansol].

Mallarmé, Stéphane (1998), OEuvres complètes. Paris, Gallimard. Bibl. de la Pléiade.

Paula Mendes Coelho é Comparatista de formação (Mestrado em Estudos Literários Comparados; Doutoramento em Estudos Franceses, na especialidade da Literatura Comparada). Docente do Departamento de Humanidades da Universidade Aberta. Coordenadora da Licenciatura em Estudos Artísticos e do Mestrado em Estudos Comparados-Literatura e outras Artes. Membro integrado do Centro de Estudos Comparatistas da Fac. Letras Univ. de Lisboa (CEC/FLUL) ; colaboradora do IELT-CEIL (FCSH, Univ. Nova de Lisboa). Domínios de Investigação : Literatura Comparada (séc. XIX- 
Paula Mendes Coelho

XXI); Simbolismo francês e belga ; Estudos Interartes; Estudos de Tradução. Nos últimos anos: as obras de Maria Gabriela Llansol e Fernando Pessoa. Autora de Questões de poética simbolista-do Romantismo à Modernidade (FCT/FCG, 2006); artigos e ensaios no âmbito dos Estudos Comparados. Orientação científica (mestrado, dout. e pós-dout.). Membro de várias Associações literárias e Conselhos editoriais nacionais e internacionais. Desde há muito que desenvolve actividades no âmbito da "Promoção da Leitura". Vice-Presidente da Coordenação Científica do "Congresso Internacional Mário Dionísio. No centenário do seu nascimento "Como uma pedra no silêncio..." (27-30 de Outubro de 2016. Org. CECFLUL/Centro Mário Dionísio/Museu do Neo-Realismo). Membro do Júri do Prémio de Romance e Novela da Associação Portuguesa de Escritores-APE (2016). 